\title{
Comparative Study of the Immunological Marker IL-6 and the Non- Immunological Marker PCT in Surgery Patients with Infections and Multiple Trauma
}

\author{
Sieglinde Zelzer ${ }^{*}, 1$, Reingard M. Aigner ${ }^{2}$, GholamAli Khoschsorur ${ }^{1}$, Herwig P. Hofer ${ }^{3}$, \\ Rudolf J. Schaur ${ }^{4}$ and Zeno Foldes-Papp ${ }^{*}, 5$ \\ ${ }^{I}$ Clinical Institute of Medical and Chemical Laboratory Diagnostics, Medical University of Graz, Austria \\ ${ }^{2}$ Department of Nuclear Medicine, Medical University of Graz, Austria \\ ${ }^{3}$ Division of Traumatology, Medical University of Graz, Austria \\ ${ }_{4}^{4}$ Institute of Molecular Bioscience, Medical University of Graz, Austria \\ ${ }^{5}$ Department of Molecular Biology and Immunology, Health Science Center, University of North Texas, USA
}

\begin{abstract}
The objective of this study was to assess and to compare the time course of the immunological signaling marker IL-6 and the non-immunological marker PCT in surgical patients with local and systemic bacterial infections and with multiple trauma of well-defined severity. 45 surgical and 26 intensive care patients were enrolled in this collaborative study. We analyzed IL-6 and PCT blood concentrations under the different experimental conditions with Cochran's $\hat{Q}$-criterion for testing null hypotheses. For the surgical patients with local infections and with systemic infections, we did not find a significant decline of IL- 6 in the time course at the confidence intervals $0.999,0.990$, and 0.950. No differences in PCT concentrations were found for the various experimental conditions. The time course of IL-6 did not change significantly with medium and high severity trauma, whereas PCT declined over time with significance levels 0.990 and 0.950 . The measurement of IL-6 is predominantly a research tool at present. There are no absolute indications for routine measurements. Regarding PCT, our results do not point to this marker as a valid predictor of bacterial infections including sepsis during the early period after trauma.
\end{abstract}

Keywords: Infection, sepsis, multiple trauma, interleukin-6, procalcitonin, intensive care patients.

\section{INTRODUCTION}

Strategies and mechanisms for host and pathogen survival in acute and persistent viral infections are well described, whereas bacterial infections are not predominantly programmed genetically to survive and propagate [1]. The presence of circulating bacteria or bacterial products such as endotoxins leads to the systemic release of cytokines such as IL-6. These cytokines are a group of small signaling proteins produced by a large variety of cells; they act upon cell surface receptors to regulate and modify cell growth, maturation and repair, as well as the acute phase response to inflammation. Although IL-6 has an important role in homeostasis, excessive production and release initiate widespread tissue injury, which can result in organ dysfunction. One of the pro-inflammatory cytokines, interleukin-6 (IL-6), plays a major role in the pathogenesis of severe infections and sepsis $[2,3]$. It is synthesized by many cells including monocytes, macrophages, fibroblasts and endothelial cells after stimulation, especially by lipopolysa-

*Address correspondence to these authors at the Clinical Institute of Medical and Chemical Laboratory Diagnostics, Medical University of Graz, Austria; E-mail: sieglinde.zelzer@klinikum-graz.at and Department of Molecular Biology and Immunology, Health Science Center, University of North Texas, USA; E-mail: zeno.foldes-papp@meduni-graz.at ccharide (LPS), tumor necrosis factor (TNF) and IL-1. In the literature, measured plasma/serum concentrations of IL-6 and in particular its time course, are inconsistent for local and systemic bacterial infections and for balanced and unbalanced IL-6 activation (no bacterial/bacterial infection) [4-6].

The non-immunological marker procalcitonin (PCT), the prohormone of calcitonin, is currently recommended as a suitable parameter to detect and to evaluate the course of bacterial, viral, fungal or parasitic infections [7-9]. Studies provide evidence that both surgical trauma and humoral mediators of inflammation may induce PCT synthesis, thereby reducing the validity and reliability of PCT as an "infection-monitoring" parameter [10-12]. In patients with multiple trauma, the PCT level provides more information than the IL-6 level since only moderate amounts of PCT are induced and higher concentrations correlate with more severe trauma [13].

After multiple trauma, the outcome is strongly related to the posttraumatic balance of the immune system. If proinflammatory mediators predominate, a systemic inflammatory response syndrome may be a consequence, and if anti-inflammatory mediators predominate, immunosuppression with ineffective clearance of microorganisms and septic complications as well as multiple organ failure (MOF) may follow $[14,15]$. 
Thus, the aim of the present study was to assess and to compare the time course of the immunological signaling marker IL-6 and the non-immunological marker PCT in surgery patients with local and systemic bacterial infections and with multiple trauma of well-defined severity.

\section{MATERIALS AND METHODOLOGY}

\section{Patients}

We obtained informed consent from all ingoing patients from the emergency room who fell into the disease criteria as described below and they were enrolled in this clinical casecontrolled study. Therefore, we received heterogeneous distributions of patient data. All received antibiotic prophylaxis during operation time $[16,17]$ (medical treatment). During hospitalization, patients who developed infections were defined by a positive microbiological culture in connection with at least one of the clinical or laboratory findings as laid down by the American College of Chest Physicians/Society of Critical Care Medicine Consensus Conference [18].

Surgical patients: After approval from the Research Ethics Committee of the Medical University of Graz for the masked prospective study, 45 surgical patients ( 29 men aged $54.6 \pm 15.7$ years and 16 women aged $58.2 \pm 16.3$ years) from the Department of Surgery were enrolled and divided into three groups. The control group (group S1) consisted of 15 surgical patients without bacterial complications undergoing operations (medical treatment) for obesity, hernia, or cancer of the stomach, pancreas or colon. Patients in groups S2 and S3 had febrile conditions, e.g. gangrene of the leg with circulatory disorder, cystitis, purulent appendicitis, abscess or ulcer. Group S2 consisted of 17 surgical patients with local infections before surgery and group S3 comprised 13 surgical patients with systemic infections before surgery. In addition, we should mention that the one non-survivor, who was excluded from the study, was a patient with gangrene of the leg who died 2 days after surgery. He exhibited a 17-fold increase of IL-6 concentration at day one after surgery with a further increase the next day. The PCT concentration was increased by a factor of 600 compared to the control group on both days.

Trauma patients: Twenty-six multiple trauma patients from the Intensive Care Unit (ICU) were enrolled. Eighteen male (mean age $37.8 \pm 16.7$ years) and 8 female patients $(29.1 \pm 12.8$ years $)$ were included from routine admissions and selected according to trauma severity. The patients had suffered traffic, industrial or sport accidents with multiple traumas to bones, soft tissue, visceral organs and the central nervous system. Patients with severe head trauma were excluded, as were patients who died or left the area. The control group (group T1) included eight patients with low trauma severity; their Injury Severity Score (ISS) was between 15-20. Ten patients with moderately severe trauma (ISS of 21-30) were enrolled in group T2. Group T3 consisted of 8 patients with very severe trauma (ISS > 30). Nine trauma patients developed infections during hospitalization while 17 patients were free of infection.

\section{Experimental Methods}

Blood samples from surgical patients were collected by aspiration in Vacutainer ${ }^{\circledR}$ tubes immediately before surgery (-1) and postsurgically at days 1, 3 and 5. Trauma patients' blood was drawn as soon as possible after trauma (day one after trauma) and daily thereafter between 8:00 and 10:00 a.m. from a central venous catheter or a cubital vein until discharge from the intensive-care unit. Plasma and serum samples were centrifuged and stored at $-70^{\circ} \mathrm{C}$ until analysis.

\section{Total IL-6}

A commercially available ELISA kit (Quanti-Glo IL-6 Immuno-Assay, R\&D Systems, Minneapolis, MN, USA) was used to measure bound and free IL- 6 in lithium heparinate plasma. This assay employs the quantitative sandwich enzyme immunoassay technique. The concentration of IL- 6 was also calculated from the standard curve. The minimum detectable dose of IL-6 is less than $0.2 \mathrm{ng} / \mathrm{l}$.

\section{PCT}

PCT was measured in serum by an immunoluminometric assay ("LUMItest PCT", Brahms Diagnostica GmbH, Berlin, Germany). The principle of measurement was described by Molz P. [19]. The concentration of PCT was calculated from the standard curve. The detection limit of this assay is $0.1 \mu \mathrm{g} / \mathrm{l}$.

\section{Mathematical Analyses of the Measured Experimental Data [20]}

The normal concentration ranges for IL- 6 and PCT in human plasma and serum, respectively, were obtained from Endler et al. and Saribas et al. respectively [21,22]. These authors used the same assay conditions for the IL-6- and PCT-ELISAs as we applied (see above) such as manufacturers, buffers, incubations, washing steps, detection antibodies, etc. For healthy donors, the minimum-maximum levels are as follows: $0.8-2.4 \mathrm{ng} / 1 \mathrm{IL}-6$, and $0.12-0.71 \mu \mathrm{g} / 1$ PCT. Measured IL-6 plasma concentrations of $\leq 2.4 \mathrm{ng} / \mathrm{l}$ and measured PCT serum concentrations of $\leq 0.71 \mu \mathrm{g} / 1$ were considered non-elevated. Measured IL-6 plasma concentrations of $>2.4 \mathrm{ng} / \mathrm{l}$ and measured PCT serum concentrations of $>0.71 \mu \mathrm{g} / \mathrm{l}$ were considered elevated.

We properly analyzed the variable $X$ under $p$ experimental conditions (dependent trials) in $n$ patients/individuals. Thus, we had the $n \times p$ matrices $\mathbf{X}$ with $n$ rows and $p$ columns

$$
\mathbf{X}_{n \times p \geq 30}=\left(\begin{array}{ccccc}
x_{11} x_{12} & \cdots & x_{1 j} & \cdots & x_{1 p} \\
x_{21} x_{22} & \cdots & x_{2 j} & \cdots & x_{2 p} \\
\vdots & \vdots & \vdots & & \vdots \\
x_{i 1} x_{i 2} & \cdots & x_{i j} & \cdots & x_{i p} \\
\vdots & \vdots & \vdots & & \vdots \\
x_{n 1} x_{n 2} & \cdots & x_{n j} & \cdots & x_{n p}
\end{array}\right)
$$


The

$x_{\bullet i}=\sum_{j=1}^{p} x_{i j}, i=1,2, \cdots, n$

positive observations 1 (elevated levels of blood concentrations) in the individual $i$ were $\left(\begin{array}{l}p \\ x_{\bullet i}\end{array}\right)$-fold distributed over the $p$ different, dependent trials (experimental conditions). If the null hypothesis $H_{0}$ applied, then each of these possible patterns (distributions) was equally realized in the experimental data set of elevated (1) and non-elevated $(0)$ levels of blood concentrations. Under some alternative hypothesis $H_{A}$, the variables

$x_{\bullet j}=\sum_{i=1}^{n} x_{i j}, j=1,2, \cdots, p$

diverged from their mean value $\left\langle x_{\bullet j}\right\rangle$.

The $x_{\bullet i}=0$ and $x_{\bullet i}=p$, which did not contribute to the discrimination between $H_{0}$ and $H_{A}$, were omitted. We obtained the following four matrices

$\mathbf{T}=\mathbf{X}^{\mathrm{T}} \cdot \mathbf{1}, \mathbf{T}^{2}$, with $j=1,2, \cdots, p ;$

$\mathbf{L}=\mathbf{X} \cdot \mathbf{1}, \mathbf{L}^{2}$, with $i=1,2, \cdots, n$.

$\mathbf{1}$ is the unit vector. ${ }^{\mathrm{T}}$ denotes the transpose of $\mathbf{X}$. Then, the Cochran's $\hat{Q}$-criterion for testing the null hypothesis in the $p \geq 2$ dependent trials was calculated as follows

$\hat{Q}=\left(\lambda \cdot\left[p \cdot\left(\mathbf{T}^{2}\right) \cdot \mathbf{1}-\mathbf{T}^{\mathrm{T}} \cdot \mathbf{1}\right]\right) /\left(p \cdot \mathbf{T}^{\mathrm{T}} \cdot \mathbf{1}-\left(\mathbf{L}^{2}\right)^{\mathrm{T}} \cdot \mathbf{1}\right)$, with $\lambda=p-1$. (Eqn. 6)

Values of $\hat{Q}<\chi_{\alpha ; \lambda}^{2}$ with $\alpha=0.05,0.01$, or 0.001 were considered for keeping the null hypothesis $\hat{Q}<\chi_{\alpha ; \lambda}^{2} \rightarrow H_{0}$ that the true mean differences to the mean values $\left\langle x_{\bullet j}\right\rangle$ approached zero against some alternative hypothesis $H_{A}$. In the case of $\hat{Q} \geq \chi_{\alpha ; \lambda}^{2} \rightarrow H_{0}$ was rejected and $H_{A}$ was significant within the confidence intervals $1-\alpha=0.950,0.990$, or 0.999 as indicated. The quantitative analyses directly compared the raw data under the different experimental conditions $p$ of $n$ individuals or patients (subjects) in the patient groups $\mathrm{S}_{1}, \mathrm{~S}_{2}, \mathrm{~S}_{3}, \mathrm{~T}_{1}, \mathrm{~T}_{2}, \mathrm{~T}_{3}$

\section{RESULTS}

The IL-6 and PCT human blood concentrations were determined by commercially available ELISAs from R\&D (USA) and Brahms Diagnostica (Germany). Reference sera (calibrators), positive and negative controls, cut-off points, calibration curves, intra-assay and inter-assay precisions were provided by the specified suppliers. We remeasured and confirmed all analytical values of assay quality control. All assays were performed in duplicate.
In order to properly analyze the complex, heterogeneous experimental conditions in the clinical, case-controlled study, it was necessary to represent the median and the ranges of the measured IL-6 and PCT concentrations (Table 1).

Time Course of IL-6 and PCT in Surgery Patients without Infection and with Local and Systemic Infection After Medical Treatment

The measured median values and ranges of the IL- 6 and PCT blood concentrations are shown in Table 1A for the period from immediately before surgery (day -1) until day 5 after surgery.

\section{$I L-6$}

In the control group S1 without bacterial complications undergoing operations (medical treatment) for obesity, hernia, or cancer of the stomach, pancreas or colon, a measured trend for increased IL-6 plasma concentrations over time was observed within the confidence interval 0.999 as depicted in Table 2: $\mathrm{S} 1 \rightarrow \hat{Q}=17.478$ $>\chi_{0.001 ; \lambda=3}^{2}=16.30$. Thus, there was evidence indicating a real difference in the time course from days 1,3 , and 5 compared with the outcome before medical treatment on day -1 at the 0.001 level of significance. No significant differences in the time course were found at the confidence intervals $0.999,0.990$, and 0.950 for group S2 consisting of 17 surgical patients with local infections and group S3 consisting of 13 surgical patients with systemic infections. Thus, IL-6 is not an indicator or specific parameter for local and systemic bacterial infections in surgery patients.

$P C T$

No differences were found between the experimental conditions of the PCT serum concentrations (dependent trials) in the patients in groups S1, S2 and S3 at the confidence intervals $0.999,0.990$, and 0.950 (Table 2).

\section{Time Course of IL-6 and PCT in Trauma Patients}

The measured median values and ranges of the IL- 6 and PCT blood concentrations from days +1 to +7 after trauma are shown in Table 1B.

IL-6

Comparing the IL-6 plasma concentrations in the posttraumatic period, there were no significant changes or trends toward a decrease in IL-6 in patients with low (T1), medium (T2) and high (T3) severity trauma, as can be inferred from Table 2 .

PCT

Differences in PCT serum concentrations were observed in the post-traumatic period in patients with medium (T2) and high (T3) severity of trauma. The significance levels were 0.990 and 0.950 as shown in Table $2:$ T2 $\rightarrow \hat{Q}=18.00$ $>\chi_{0.05 ; \lambda=6}^{2}=12.60, \chi_{0.01 ; \lambda=6}^{2}=16.80$ and $\mathrm{T} 3 \rightarrow \hat{Q}=19.826$ $>\chi_{0.05 ; \lambda=6}^{2}=12.60, \chi_{0.01 ; \lambda=6}^{2}=16.80$. At the confidence interval of 0.999 , there was no trend in the time course of 
Table 1. Median and Ranges of IL-6 and PCT in Surgery Patients without Infection (Group 1), with Local (Group 2) and Systemic Infection (Group 3) Before Surgical Operation (-1) and at Day 1, 3 and 5 After Operation (Table 1A) and Polytrauma Patient with Different Trauma Severity (Group 1: ISS 15-20; Group 2: ISS 21-30; Group 3: ISS > 30) at Day 1, 2, 3, 4, 5, 6 and 7 After Trauma (Table 1B)

Table 1A

\begin{tabular}{|c|c|c|c|c|}
\hline \multicolumn{5}{|c|}{ Surgery Patients } \\
\hline \hline IL-6 (ng/l) & -1 & +1 & +3 & +5 \\
\hline Group S1 & $0.8(0.2-8.2)$ & $8.8(1.2-74.8)$ & $4.0(1.3-141.0)$ & $2.9(1.4-10.6)$ \\
\hline Group S2 & $5.8(0.2-70)$ & $12.9(0.7-73)$ & $7.8(0.7-89)$ & $6.4(0.4-24)$ \\
\hline Group S3 & $8.4(3.7-341)$ & $16.1(5.6-362)$ & $15.5(2.6-793)$ & $11.1(1.9-279)$ \\
\hline PCT $(\mu \mathrm{g} / \mathrm{l})$ & & & & $0.15(0.11-1.2)$ \\
\hline Group S1 & $0.15(0.07-0.23)$ & $0.21(0.12-7.2)$ & $0.17(0.01-2.0)$ & $0.13(0.10-1.8)$ \\
\hline Group S2 & $0.13(0.09-1.60)$ & $0.17(0.01-22.9)$ & $0.15(0.11-2.1)$ & $0.23(0.10-17.8)$ \\
\hline Group S3 & $0.33(0.11-16.3)$ & $0.40(0.11-23.1)$ & $0.34(0.11-36.0)$ & \\
\hline
\end{tabular}

Table 1B

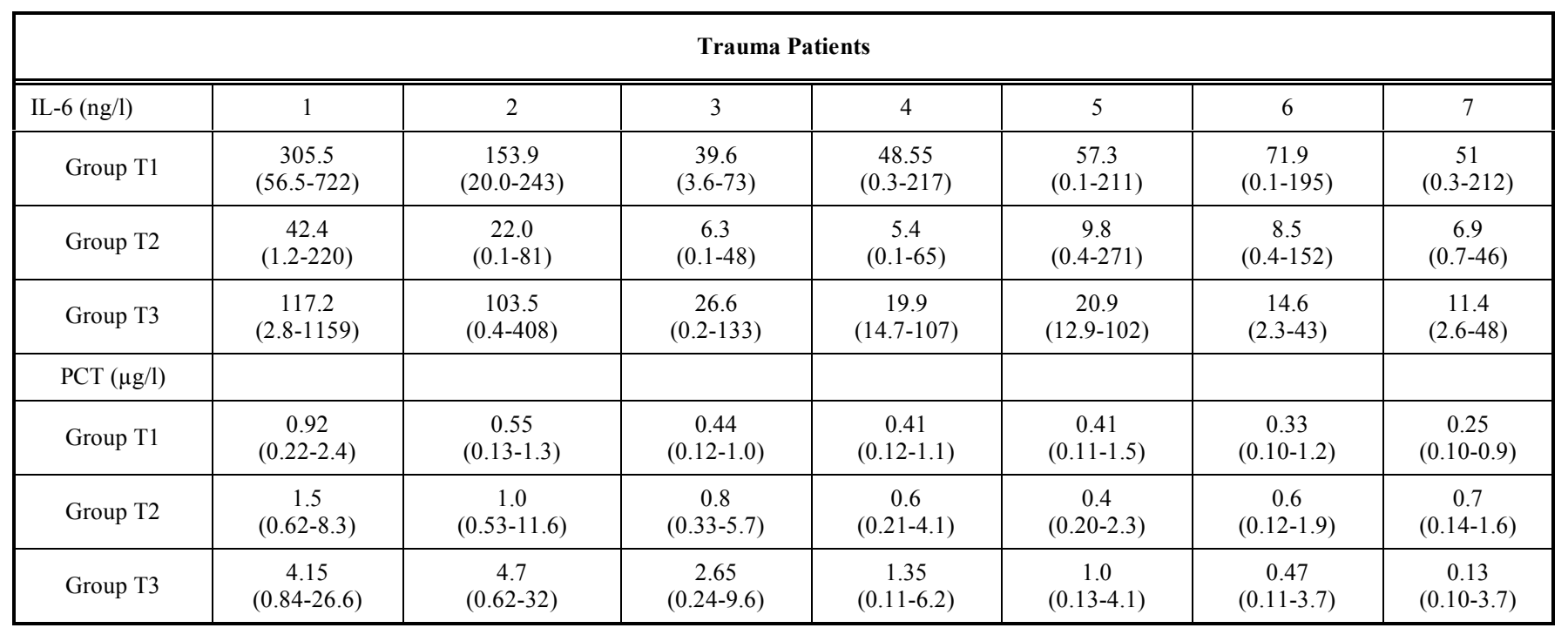

PCT serum concentrations between the trials in groups T1, T2 and T3.

\section{Comparison of IL-6 and PCT Values in Four Selected Patients with Posttraumatic Infections}

To demonstrate the interesting observation that some of the patients developed infections under the proper medical treatment (see Materials and Methods, subsection Patients) after the initial trauma, in Fig. (1) we separately present 4 patients who developed bacterial infections within 9 days after trauma. IL-6 in patient 59 (T2) showed a marked increase of 65 to $270.5 \mathrm{ng} / \mathrm{l}$ (roughly 27 to 113 times the normal range) one day before clinical manifestation. IL-6 levels from patient 53 (T1) showed constant values around 50ng/l beginning from day 3 and continuing to day 6 after trauma. Patient 56 (T2) had an increased level (40ng/l) on day 8 , which thereafter returned to the normal range. IL-6 in patient 62 (T2) showed a moderate increase on day 9 after trauma (of 7 to $24 \mathrm{ng} / \mathrm{l}$ ). PCT did not reveal a significant
Table 2. $\hat{Q}$-Values Under the Different Experimental Conditions $p=\lambda+1$

\begin{tabular}{|c|c|c|}
\hline Patient Group & IL-6 & PCT \\
\hline \hline S1 & $17.478(\lambda=3)$ & $3.000(\lambda=3)$ \\
\hline S2 & $4.385(\lambda=3)$ & $3.000(\lambda=3)$ \\
\hline S3 & $3.000(\lambda=3)$ & $4.714(\lambda=3)$ \\
\hline T1 & $11.571(\lambda=6)$ & $8.710(\lambda=6)$ \\
\hline T2 & $10.364(\lambda=6)$ & $18.000(\lambda=6)$ \\
\hline T3 & $7.500(\lambda=6)$ & $19.826(\lambda=6)$ \\
\hline
\end{tabular}

The null hypotheses are maintained for

$\hat{Q}<\chi_{\alpha} ; \lambda$ with $\chi_{0.05 ; \lambda=3}^{2}=7.82, \chi_{0.01 ; \lambda=3}^{2}=11.30, \chi_{0.001 ; \lambda=3}^{2}=16.30$,

$\hat{Q}<\chi_{\alpha ; \lambda}$ with $\chi_{0.05 ; \lambda=6}^{2}=12.60, \chi_{0.01 ; \lambda=6}^{2}=16.80, \chi_{0.001 ; \lambda=6}^{2}=22.60$.

Further details of the analyses are given in the Method sections and in Földes-Papp et $a l$. Lack of specific immunological disease pattern in vulvar lichen sclerosus, Exp Mol Pathol 2005; 79: 176-85 [20]. 
trend over time between the different experimental conditions (trials) in T1, T2, T3 (confidence interval 0.999).. Therefore PCT did not indicate an infection in any of these four trauma patients. The special behaviour of the measured IL-6 and PCT values in these patients did not influence the outcome of the observed trends in the time course of trauma patients (Table 2).
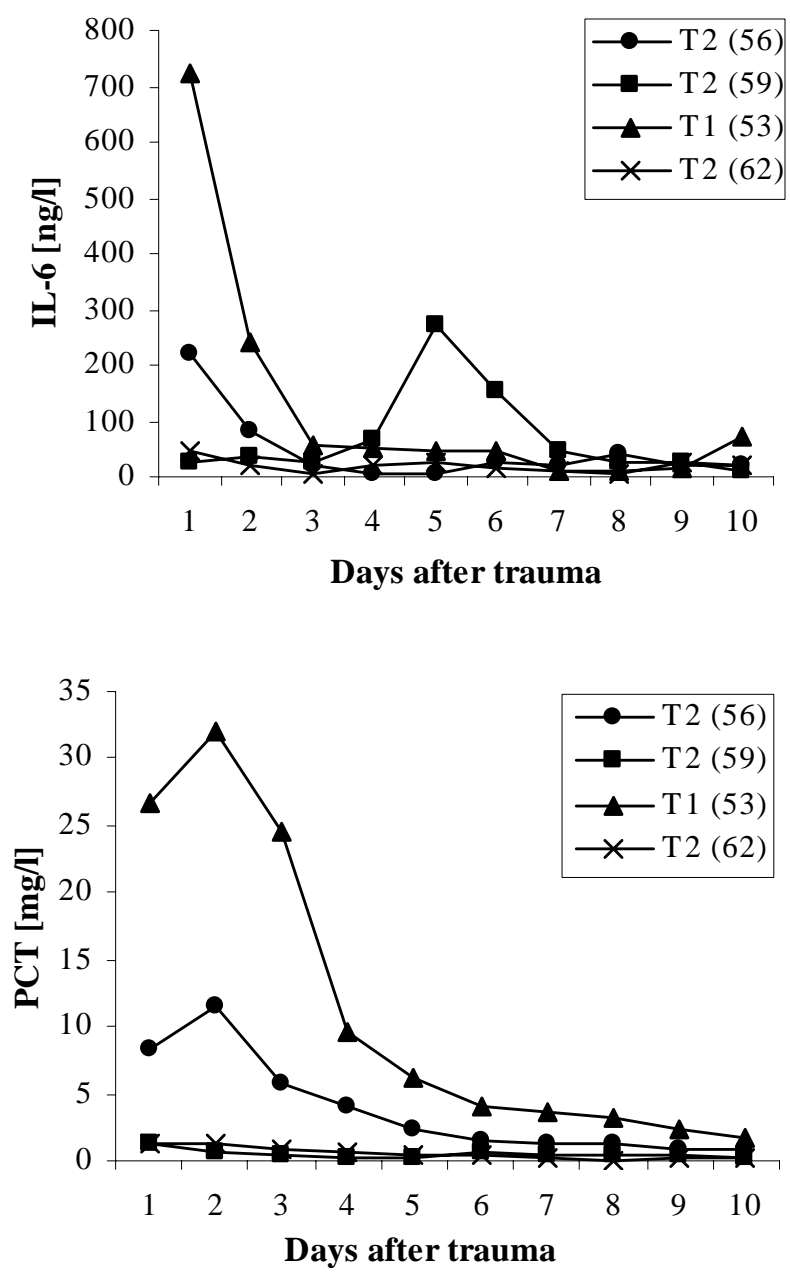

Fig. (1). Time course of IL-6 and PCT values from 4 trauma patients with infection. Circle: trauma patient (P56) of group T2 with infection clinically diagnosed on day 9; Square: trauma patient (P59) of group T2 with infection clinically diagnosed on day 6; Triangle: trauma patient (P53) of group T1 with infection clinically diagnosed on day 6; Cross: trauma patient (P62) of group T2 with infection clinically diagnosed on day 9 .

\section{DISCUSSION}

We compared blood concentrations of IL-6 and PCT in surgical patients with and without bacterial infections and with multiple trauma.

\section{IL-6}

The control group (group S1) consisted of 15 surgical patients without bacterial complications undergoing operations (medical treatment) for obesity, hernia or cancer of the stomach, pancreas or colon. Patients in groups S2 and S3 had febrile conditions, e.g. gangrene of the leg with circulatory disorder, cystitis, purulent appendicitis, abscess or ulcer. Group S2 consisted of 17 surgical patients with local infections before surgery and group S3 comprised 13 surgical patients with systemic infections before surgery. In both of these groups (S2 and S3), IL-6 concentrations were similar from day 1 to day 5 after surgery. If we look, however, at patients without bacterial complications, we find a highly significant trend of IL-6 increase during the observation interval of days 1 to 5 after surgery. Hence, IL-6 is not a specific marker (indicator) for infections at all. IL-6 is rather an unspecific parameter in response to unbalanced activation (no bacterial infection/bacterial infection). In patients with community-acquired pneumonia, Kellum et al. found that IL-6 was elevated with severe sepsis and low without sepsis, while it was high with infections but did not differ from severe sepsis, meaning that IL-6 cannot be seen as a diagnostic marker. The circulating cytokine response to pneumonia was heterogeneous and continued for more than a week after presentation, with considerable overlap between those who did and did not develop severe sepsis [5]. These observations found in patients with community-acquired pneumonia are in line with our data from surgery patients with local infection (S2) and systemic infection (S3), i.e. sepsis, as summarized in Tables $\mathbf{1 A}$ and $\mathbf{2}$. For predicting postoperative infections following major gastrointestinal surgery, Müller J. described IL-6 serum concentrations that were significantly higher in patients with infections than without but found that IL-6 was not suitable for discrimination of postoperative infections [23]. In contrast to these studies, Igonin et al. is in favour of IL-6 as marker for severity and time course of systemic inflammatory response in severe community-acquired pneumonia [24].

For non-infection based alterations, we investigated patients with multiple trauma of different severities (T1, T2, T3, see methods). The patients had suffered traffic, industrial or sports accidents with multiple traumas to bones, soft tissue, visceral organs and the central nervous system. There was indeed an increase in IL-6 plasma concentrations (Table 1B) in patients after trauma (in all three groups with different trauma severity, T1, T2, T3) but this does not indicate the relevance of IL-6 in posttraumatic monitoring. This finding is in agreement with the results of previous studies [25, 26]. However, a recent study from Billeter et al. [27] shows a significant association between IL-6 and infectious complication in trauma patients. Studying the time course of the IL-6 plasma concentrations in the posttraumatic period revealed no significant changes in our trauma patients. These findings are in good agreement with the results of Tschoeke et al. [28]. Trauma patients with blunt multiple injuries who did not receive immediate surgical care demonstrated declining IL-6 concentrations 24 hours after admission, whereas patients undergoing immediate surgical treatment showed significantly increased IL-6 plasma concentrations on day 1 after trauma. Tschoeke et al. did not extend the observation time 24 hours posttrauma (day 1). In patients undergoing different kinds of cardiothoracic surgical procedures, Franke et al. found that IL-6 serum concentration is increased until day 5 after surgery, which was the maximum observation time for IL-6 [29]. 


\section{PCT}

The PCT serum concentrations (Tables $\mathbf{1 A}$ and 2) were not elevated with time after surgery in patients with bacterial infections (S2 and S3 groups) and without infection (S1 control group). Other reports indicate, that PCT levels rather than conventional inflammatory parameters and IL-6 more reliably indicate sepsis in patients admitted with systemic inflammations $[10-12,30,31]$. Our findings do not confirm a correlation between PCT increase in human serum and severe sepsis.

PCT values are elevated with moderate (T2) and severe (T3) trauma (Tables $\mathbf{1 B}$ and 2) and normalize after surgery. In patients undergoing pulmonary resection, Hoksch et al. demonstrated an increase in PCT after surgical trauma followed by rapid normalization in patients with an uncomplicated course (i.e. without infections) during the postoperative period of days 1-5 [32]. Meisner et al. report that the severity of trauma correlates with PCT concentration and that the latter can serve to differentiate postoperative complications [33]. Other reports also show that PCT may be an indicator of injury and systemic inflammation in polytraumatized patients during the posttraumatic period [27, 34].

In conclusion, our results do not point to PCT as an indicator or marker that is valid for prediction of bacterial infections including sepsis during the early period after trauma.

Regarding IL-6, the measurement of this marker is predominantly a research tool at present. Thus, interest has focused on the role of IL- 6 formation under pathological circumstances, but the use of IL-6 as predictive marker of infection may be limited.

\section{ACKNOWLEDGEMENTS}

We thank Ms. Eugenia Lamont for editorial assistance and Dr. Beatrix Kirsten, Brahms Diagnostica, for literature search.

Supported, in part, by the Forschungsförderungsfond für die Gewerbliche Wirtschaft, Austria. Z.F.-P. acknowledges financial support from the FWF Austrian Science Fund, project number P20454-N13. The authors have not disclosed any potential conflicts of interest.

\section{REFERENCES}

[1] Hilleman MR. Strategies and mechanisms for host and pathogen survival in acute and persistent viral infections. Proc Natl Acad Sci USA 2004; 101: 14560-6.

[2] Heinrich PC, Castell JV, Andus T. Interleukin-6 and acute phase response. J Biochem 1990; 265: 621-36.

[3] Billiau A, Vandekerckhove F. Cytokines and their interactions with other inflammatory mediators in the pathogenesis of sepsis and septic shock. Eur J Clin Invest 1991; 21: 559-73.

[4] Haupt W, Hohenberger W, Mueller R, Klein P, Christou NV. Association between preoperative acute phase response and postoperative complications. Eur J Surg 1997; 163: 39-44.

[5] Kellum JA, Kong L, Fink MP, et al. Understanding the inflammatory cytokine response in pneumonia and sepsis: results of the Genetic and Inflammatory Markers of Sepsis (GenIMS) Study. Arch Intern Med 2007; 167: 1655-63.

[6] Selberg O, Hecker H, Martin M, Klos A, Bautsch W, Köhl J. Discrimination of sepsis and systemic inflammatory response syndrome by determination of circulating plasma concentrations of procalcitonin, protein complement $3 \mathrm{a}$, and interleukin-6. Crit Care Med 2000; 28: 2793-8.

[7] Meisner M. Procalcitonin (PCT) a new, innovative infection parameter. Biochemical and clinical aspects. New York: Thieme, Stuttgart 2000.

[8] Assicot M, Gendrel D, Carsin H, Raymond J, Guilbaud J, Bohuon C. High serum procalcitonin concentration in patients with sepsis and infection. Lancet 1993; 341: 515-8.

[9] Simon L, Gauvin F, Amre DA, Saint-Louis P, Lacroix J. Serum procalcitonin and $\mathrm{C}$ - reactive protein levels as markers of bacterial infection: A systemic review and metaanalysis. Clin Infect Dis 2004; 39: 206-17.

[10] Meisner M, Tschaikowsky K, Hutzler A, Schick C, Schüttler J. Postoperative plasma concentrations of procalcitonin after different types of surgery. Intensive Care Med 1998; 24: 680-4.

[11] Molter GP, Soltesz S, Kottke R, et al. Procalcitonin plasma concentrations and systemic inflammatory response following different types of surgery. Anaesthesist 2003; 52: 210-17.

[12] Lindberg M, Hole A, Johnsen H, et al. Reference intervals for procalcitonin and $\mathrm{C}$-reactive protein after major abdominal surgery. Scand J Clin Lab Invest 2002; 62: 189-94

[13] Nast-Kolb D, Waydhas C, Gippner-Steppert C, et al. Indicators of the posttraumatic inflammatory response correlate with organ failure in patients with multiple injuries. J Trauma 1997; 42: 44655 .

[14] Svoboda P, Kantorova I, Ochmann J. Dynamics of interleukin 1, 2 and 6 and tumor necrosis factor alpha in multiple trauma patients. J Trauma 1994; 36: 336-40.

[15] Perl M, Gebhard F, Knöferl MW, et al. The pattern of preformed cytokines in tissues frequently affected by blunt trauma. Shock 2003; 19: 299-304

[16] Egger G, Burda A, Mitterhammer H, Baumann G, Bratschitsch G, Glasner A. Impaired blood polymorphonuclear leukocyte migration and infection risk in severe trauma. J Infect 2003; 47: 148-54.

[17] Egger G, Aigner R, Glasner A, Hofer HP, Mitterhammer H, Zelzer $\mathrm{S}$. Blood polymorphonuclear leukocyte migration as a predictive marker for infections in severe trauma: comparison with various inflammation parameters. Intensive Care Med 2004; 30: 331-4.

[18] Muckard DJ, Bhagwanjee S. American College of Chest Physicians/Society of Critical Care Medicine Consensus Conference definitions of the systemic inflammatory response syndrome and allied disorders in relation to critically injured patients. Crit Care Med 1997; 25: 1789-95.

[19] Molz P. Luminescence: marking with light. Diagn Labour 1991; 41: 41-6.

[20] Földes-Papp Z, Reich O, Demel U, Tilz GP. Lack of specific immunological disease pattern in vulvar lichen sclerosus. Exp Mol Pathol 2005; 79: 176-85.

[21] Endler G, Marsik C, Joukhadar C, et al. The interleukin-6 G(174)C promoter polymorphism does not determine plasma interleukin-6 concentrations in experimental endotoxemia in humans. Clin Chem 2004; 50: 195-200.

[22] Saribas S, Kocazeybek B, Aslan M, et al. Do procalcitonin and Creactive protein levels have a place in the diagnosis and follow-up of Helicobacter pylori infections? J Med Microbiol 2004; 53: 63944.

[23] Müller J. Efficacy of National Nosocomial Infection Surveillance score, acutephase proteins, and interleukin-6 for predicting postoperative infections following major gastrointestinal surgery. Sao Paulo Med J 2007; 125: 34-41.

[24] Igonin AA, Armstrong VW, Shipkova M, Lazareva NB, Kukes VG, Oellerich M. Circulating cytokines as markers of systemic inflammatory response in severe community-acquired pneumonia. Clin Biochem 2004; 37: 204-9.

[25] Gebhard F, Pfetsch H, Steinbach G, Strecker W, Kinzl L, Brückner UB. Is interleukin 6 an early marker of injury severity following major trauma in humans? Arch Surg 2000; 135: 291-5.

[26] Casey LC, Balk RA, Bone RC. Plasma cytokine and endotoxin levels correlate with survival in patients with the sepsis syndrome. Ann Intern Med 1993; 119: 771-8.

[27] Billeter A, Turina M, Seifert B, Mica L, Stocker R, Keel M. Early serum procalcitonin, interleukin-6, and 24-hour lactate clearance: useful indicators of septic infections in severely traumatized patients. World J Surg 2009; 33: 558-66. 
[28] Tschoeke SK, Hellmuth M, Hostmann A, Ertel W, Oberholzer A. The early second hit in trauma management augments the proinflammatory immune response to multiple injuries. J Trauma 2007; 62: 1396-404

[29] Franke A, Lante W, Fackeldey V, et al. Pro-inflammatory cytokines after different kinds of cardio-thoracic surgical procedures: is what we see what we know? Eur J Cardiothorac Surg 2005; 28: 569-75.

[30] Tasabehji WR, Al-Quobaili FA, Al-Daher NA. Usefulness of procalcitonin and some inflammatory parameters in septic patients. Saudi Med J 2008; 29: 520-5.

[31] Pavare J, Grope I, Eihvalde L, Gardovska D. Diagnostic markers for idendifying sepsis in patients with systemic inflammatory response syndrome (SIRS): A prospective study. Open Pediatr Med J 2009; 3: 1-7.

[32] Hoksch B, Fahrner R, Alexander Schmid R. Procalcitonin and brain natriuretic peptide as parameters in the postoperative course of patients with major pulmonary resection. Interact Cardiovasc Thorac Surg 2007; 6: 155-159.

[33] Meisner M, Adina H, Schmidt J. Correlation of procalcitonin and C-reactive protein to inflammation, complications and outcome during the intensive care unit course of multiple trauma patients. Crit Care 2006; 10: R1.

[34] Maier M, Wutzler S, Lehnert M, et al. Serum procalcitonin levels in patients with multiple injuries including visceral trauma. J Trauma 2009; 66: 243-9.

(C) Zelzer et al.; Licensee Bentham Open.

This is an open access article licensed under the terms of the Creative Commons Attribution Non-Commercial License (http: //creativecommons.org/licenses/by-nc/ 3.0/) which permits unrestricted, non-commercial use, distribution and reproduction in any medium, provided the work is properly cited 